\title{
Application of Energy Storage Technology in Photovoltaic Power Generation System
}

\author{
Zhilin Ding, Wenping Bu, Renbo Xu and Shuling Feng \\ (NanChang Institute of Science and Technology, Nanchang,330108)
}

\begin{abstract}
Keywords: Energy storage technology; Photovoltaic power generation; Distributed generation; Power system
\end{abstract}

\begin{abstract}
With the development of energy storage technology and the advancement of corresponding technologies, various new energy technologies consider energy storage as an important part of their energy management. This paper introduces the types of energy storage technologies and practical applications of energy storage technologies and describes the compensation function of the energy storage technology to the power network. Finally, the topological circuit of the energy storage technology in photovoltaic power generation system is compared and analyzed, and the features of decentralized management and centralized management are described.
\end{abstract}

\section{Introduction}

In recent years, governments of all countries have put renewable energy generation on the agenda in response to energy crisis and environmental safety issues. According to the statistics plan of the European Union and the United States, renewable energy sources account for more than $20 \%$ of total energy consumption by 2020 . The Chinese government has responded positively to the energy call and plans to achieve a renewable energy utilization rate of $15 \%$ by 2020 . On this basis, photovoltaic power generation has been continuously developed. With the increase of power generation capacity of photovoltaic power generation, the role of energy storage technology has gradually emerged. Starting with the current status of energy storage technology application, this paper systematically illustrates the research methods of energy storage technology and the realization characteristics of photovoltaic energy storage technology.

\section{Energy Storage Technology Research Status}

Renewable energy mainly includes large-scale grid-connected generation and distributed generation. The distributed utilization of renewable energy has been rapidly developed in recent years, which is not only an important energy supply for the main power grid, but also provides a way for multiple energy sources to provide power, which is a manifestation of flexible and efficient use of multiple energy sources. The microgrid is a combination of distributed grids within a certain area. Its role is to provide heating, cooling, and power supply for the load in the area. In the use of renewable energy power generation, due to the influence of meteorological factors on wind power and photovoltaic power generation, it has intermittent and random fluctuations in the power generation process, which causes the output power in power generation process to fluctuate, forming impact to major power grid and load. Domestic and foreign scholars designed energy storage devices to suppress power fluctuations in the process of renewable energy power generation instability. At the same time, the installation of energy storage devices in the renewable energy generation process can also enhance the inertia of microgrid, improve the anti-disturbance capability of microgrid and strengthen the reliability and safety of regional grid power supply. 


\section{The Role and Category of Energy Storage Technology}

\section{Energy storage technology concept}

Energy storage refers to the efficient conversion of electrical energy through some kinds of device to other easily stored energy, and it is convenient to convert the stored energy into the required form when needed. Therefore, this process can be divided into two categories: The first category is a method for efficiently storing large amounts of energy, and the second one is for fast and efficient energy conversion. The energy transmission forms in traditional power network are: power production, power transmission and power use. This model is almost completely "rigid", and the power network after adding energy storage technology becomes "flexible" and the security, economics and flexibility of the power grid in operation will also be greatly improved. ${ }^{[3][4]}$ Users use energy storage technology to make electric energy be clean, be easy to collect, and be easily and efficiently converted to other forms of energy, etc., which has great advantages over traditional energy sources.

\section{Role of energy storage technology in modern power system}

The main functions of energy storage technology in power system include the peaking of power, the stability of maintenance system and the improvement of the quality of power grid operation. The energy storage technology plays a role in the operation of power system in the following aspects: Firstly, cutting peaks and filling valleys to improve the daily load rate of power system, to improve the utilization rate and operating efficiency of power generation equipment. Secondly, provide emergency power, which can improve system operation reliability and improve power quality, in order to prevent the power interruption in hospitals, fire, communications, banks and other major loads. In addition, the energy storage equipment can be used as an emergency power source to fight for time for power grid recovery to avoid causing greater losses. Thirdly, a frequency modulation, through the combination of energy storage equipment and advanced power conversion equipment to achieve rapid control of the power grid, can improve the static and dynamic characteristics of the power grid. Fourthly, meet the needs of renewable energy systems. Through high-performance energy storage equipment and wind power, the combination of photovoltaic power generation supports rapid switching of charge and discharge processes.

Energy storage technology control method and operation mode in photovoltaic power generation system

Electric energy can be converted into chemical energy, potential energy, kinetic energy, electromagnetic energy and other storage forms. According to the specific storage methods, it can be divided into mechanical energy, electromagnetic energy, electrochemical energy and thermal energy. Mechanical energy includes pumped energy storage, compressed air and flywheel energy storage. Chemical energy includes lead-acid, nickel-chromium, nickel-metal hydride, lithium-ion, liquid flow and sodium-sulfur. Electromagnetic energy includes superconducting, high-energy-density capacitive energy storage and supercapacitor storage energy, etc. Thermal energy storage includes molten salt energy storage and thermoelectric energy storage.

At present, the two directions of photovoltaic energy storage technology according to the application status are as follows:

First, super capacitor energy storage. Super capacitors are also called electrochemical capacitors. Super capacitors can be divided into double-layer capacitors and Faraday quasi-capacitors according to the principle of energy storage.

Second, lithium battery energy storage is based on lithium-ion battery energy storage and its energy storage characteristics can be high-density energy storage. 


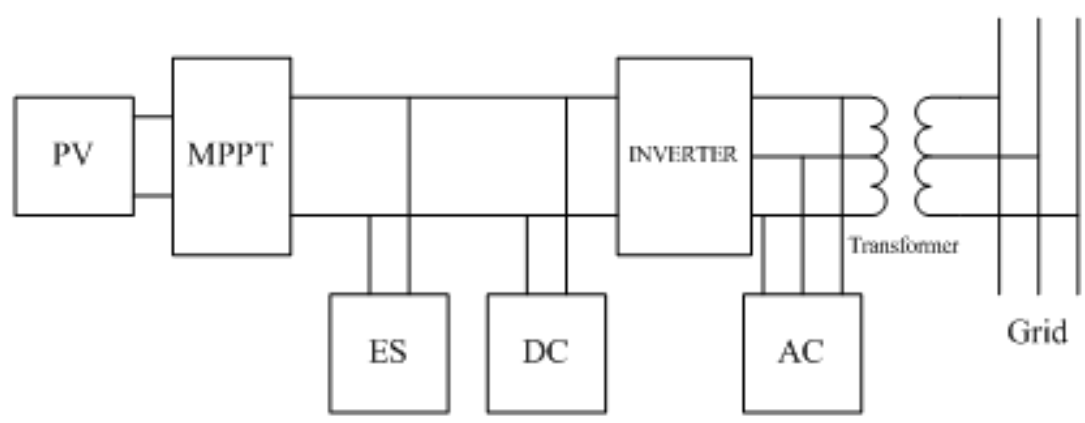

Fig.1 Structure of photovoltaic grid-connected power generation system with energy storage Photovoltaic grid-connected power generation structure with energy storage links is shown in Figure $1 .^{[11]}$ There are two ways of energy storage in microgrid with photovoltaic power supply, which are distributed and centralized. (a) and (b) of Figure 2 show the corresponding diagram. $\mathrm{P}_{\text {load }}$ is the total regional load, $\mathrm{P}_{\text {load1 }}, \mathrm{P}_{\text {load2 }} . ., \mathrm{P}_{\text {loadn }}$ are subsystem load demands. It can be known from the figure that $\mathrm{P}_{\text {load }}=\mathrm{P}_{\text {load } 1}+\mathrm{P}_{\text {load2 } 2}+\ldots+\mathrm{P}_{\text {loadn }} ; \mathrm{P}_{\mathrm{PV}}$ refers to the total photovoltaic output value, $\mathrm{P}_{\mathrm{ES}}$ is the total power configured under centralized energy storage configuration. As a result, $\mathrm{P}_{\mathrm{PV}}=\mathrm{P}_{\mathrm{PV} 1}+\mathrm{P}_{\mathrm{PV} 2}+\ldots+\mathrm{P}_{\mathrm{PVn}}$.

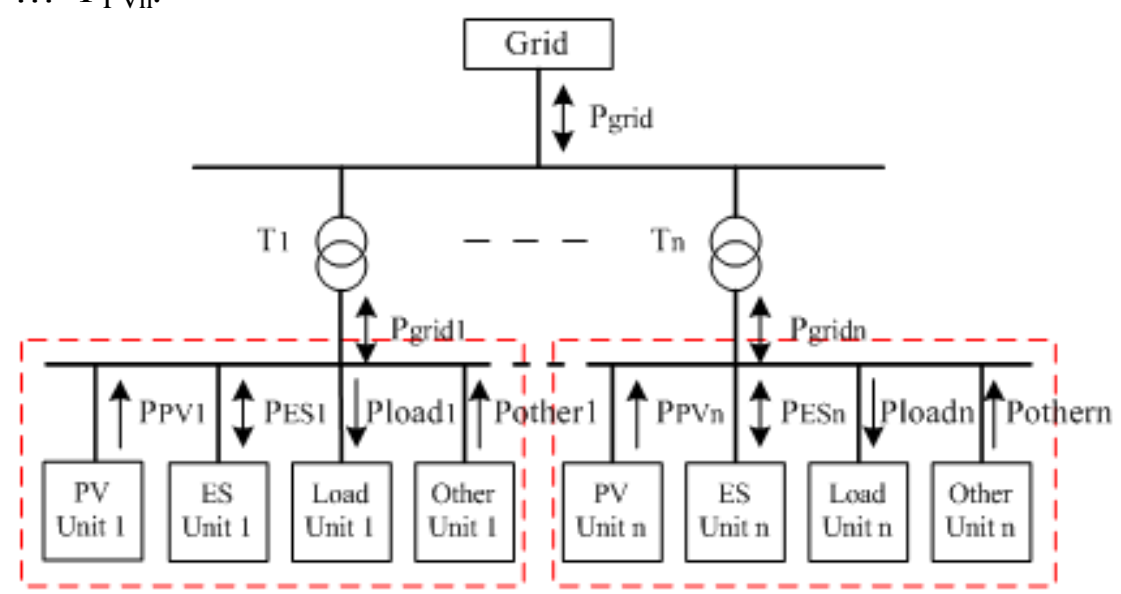

(a) Distributed Configuration of Energy Storage

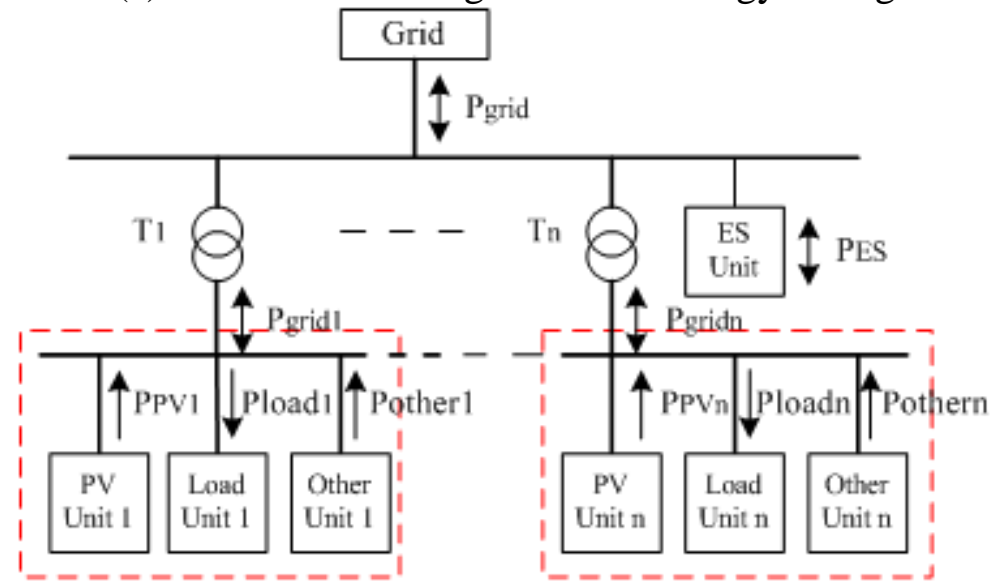

(b) Centralized Configuration of Energy Storage

Fig. 2 Schematic diagram of grid-connected microgrid system with energy storage

\section{Conclusion}

This paper describes the current application and classification of energy storage technology from the background and trends of energy storage technology. Photovoltaic power generation systems continue to develop as a form of new energy power generation. As a result, capacity continues to increase. The intervention of energy storage technologies can improve the energy instabilities in photovoltaic power generation. This paper describes the function of energy storage technology in 
the power system, and describes the operation of photovoltaic power generation system under decentralized configuration and centralized configuration.

\section{Acknowledgement}

Project funding: Nanchang DME Photoelectric Engineering Key Laboratory (No.NCZDSY -004)

\section{Reference}

[1] Peng Daofu, Research and Application of Supercapacitor Energy Storage System in Photovoltaic Power Generation System[D], Beijing Jiaotong University Master's Degree Thesis, 2011.

[2] Tong Mingsi, Research on Energy Storage Technology of Super Capacitive Power UPS[D], Harbin Institute of Technology, 2011.

[3] Luo Ni, Li Jianlin, Research Progress of Energy Storage Technology in Power System[J], Power Grid and Clean Energy, 2012.2.

[4] Cheng Shijie, Li Gang, Sun Haishun, et. al. Application and Prospect of Energy Storage Technology in Electrical Engineering[J], Power Grid and Clean Energy, 2009.2

[5] Dai Xingjian, Zhang Chaoping, Wang Shanming, et. al. Design and Experimental Research of 500kW Flywheel Energy Storage Power System [J], Power Technology, 2014.6.

[6] Hu Xuesong, Sun Caixin, Liu Ren, et al. Active Power Smoothing Control Strategy for Permanent Magnet Direct Drive Wind Turbines Using Flywheel Energy Storage[J], Automation of Power Systems, 2010.7.

[7] Zhang Xueli, Liu Qihui, Li Jianning, et. al. The Development of Energy Storage Technology and Its Application in Power System[J], Power System, 2012(12): 31

[8] Li Jianlin, Research on Control Methods of Battery Energy Storage Technology[J], Power Grid and Clean Energy, 2012.12.

[9] Hu Juan, Yang Shuili, Hou Chaoyong, Analysis and Enlightenment of Typical Demonstration Application of Scaled Energy Storage Technology[J], Power Grid Technology, 2015.4.

[10] Li Chong, Zheng Yuan, Zhou Fazhou, et. al. Application and Prospect of Energy Storage Technology in Independent Wind-solar Hybrid Power Generation System [J], Journal of Nanjing Institute of Technology, 2011.12.

[11] Lin Shaobo, Microgrid Energy Storage Control Technology with Photovoltaic Power Supply [D], PhD Dissertation of North China Electric Power University, 2013.

[12] Li Ran, Li Guangmin, Prediction of Photovoltaic Power Generation Output based on Support Vector Regression[J], China Power, 2008. 41(2): 74-78. 